\title{
El principio de la responsabilidad patrimonial y sus limitaciones
}

Mirzia Bianca $^{* *}$

\section{La relación entre responsabilidad personal y responsabilidad pa- trimonial. Crítica a la teoría del débito y la responsabilidad}

El principio de la responsabilidad patrimonial está contenido, formalmente, en el primer párrafo del artículo 2740 del Código Civil italiano, en el que se prevé de manera expresa que «el deudor responde del cumplimiento de la obligación con todos sus bienes presentes y futuros». En el segundo párrafo del mismo artículo, se dispone que «las limitaciones de la responsabilidad no se admiten sino en los casos establecidos por al ley", con lo cual se establece un impedimento a la creación de excepciones a tal principio por parte de los particulares.

El principio de la responsabilidad patrimonial consiste, entonces, en la sujeción del patrimonio del deudor al derecho de satisfacción coactiva de los créditos, ${ }^{1}$ que representa la garantía genérica de estos. La doctrina distingue tal responsabilidad de la responsabilidad personal por incumplimiento de la obligación debida, principio que se encuentra recogido

Título original: "Il principio della responsabilità patrimoniale e le sue limitazioni». Ponencia expuesta en el congreso "El Código Civil del 1984: veinte años de vigencia. Pasado y futuro», celebrado en la Pontificia Universidad Católica del Perú, del 8 al 12 noviembre del 2004.

Traducción de Leysser L. León. Profesor de Derecho Civil de la Pontificia Universidad Católica del Perú. Diplomado en Lengua y Cultura Italianas por la Università per Stranieri di Perugia (Italia).

** Profesora de Instituciones de Derecho Privado en la Università di Roma "La Sapienza».

1 Para esta definición, remitimos a BIANCA, C. M. Diritto civile, 5, La responsabilità. Milán, 1994, p. 407 y ss. 
en el artículo 1218 del Código Civil italiano, ${ }^{2}$ y que tiene como fundamento el compromiso de cooperación del sujeto deudor, ${ }^{3}$ compromiso que es considerado a tenor de criterios subjetivos de comportamiento. ${ }^{4}$

La diversidad entre las dos tipologías de responsabilidad - la primera, por incumplimiento, ligada al presupuesto de la imputabilidad; la segunda, patrimonial, de tipo objetivo-, no descarta, sino presupone, más bien, una relación de conexión entre ellas. Esta relación ha sido magníficamente ilustrada por Karl Larenz con la siguiente expresión: «La responsabilidad patrimonial sigue a la deuda como una sombra». ${ }^{5}$

Empero, dicha conexión ha sido puesta en entredicho por la conocida teoría alemana del «débito y la responsabilidad» (Schuld und Haftung). Esta teoría, partiendo de la distinción entre débito y responsabilidad — como su nombre lo indica-, llegaba a concebir la posibilidad de un débito desprovisto de responsabilidad y, viceversa, de una responsabilidad independiente de un débito. Algunas de sus aplicaciones dieron pie a que el derecho de crédito fuera considerado como el derecho sobre los bienes del deudor, al lado del cual se tenía que distinguir, autónomamente, la pretensión del cumplimiento, que se veía, así, reducida al rango de una expectativa puramente nominal. ${ }^{6} \mathrm{La}$ atención exclusiva que se prestaba a la ejecución forzosa condujo, luego, a una perspectiva parcial y limitada del concepto mismo de patrimonio, que se consideraba, exclusivamente, como «activo", con exclusión de los "pasivos», en tanto estos no son susceptibles de expropiación. ${ }^{7}$ El mérito de la teoría era, con todo e indudablemente, el de centrar

2 Remitimos aquí también a BIANCA, C. M. Op. cit., p. 11 y ss., especialmente 409. La distinción señalada también está presente en la jurisprudencia, donde se afirma que "el principio dictado en el artículo 1453 del Código Civil, que reconoce al acreedor el derecho de demandar la resolución del contrato por incumplimiento del deudor, incluso cuando se hubiera exigido el cumplimiento, no sufre excepciones ni siquiera en el caso de que el acreedor, antes de proceder para la resolución, hubiere actuado "in executivis" contra el deudor, sobre la base de títulos entregados por este último, atendiendo a que la acción ejecutiva, tal cual está prevista en los artículos 2740 y 2910 del Código Civil, no es una acción de cumplimiento, sino solamente una acción que, sobre la base de un título específico, apunta a hacer conseguir al acreedor, a través de la afectación inmediata del patrimonio del deudor que incumple, aquel resultado que él no ha podido conseguir directamente del deudor, a través del cumplimiento exacto». Esto se lee en la sentencia 4123 de la Corte di Cassazione, del 22 de marzo del 2001.

3 La adopción de este fundamento ético se encuentra, en la doctrina peruana, en FERNÁNDEZ CRUZ, G. "La obligación: Apuntes para una dogmática jurídica del concepto». ThémisRevista de Derecho, 2. ${ }^{a}$ época, n.․ㅗ 27-28, 1994, pp. 41-56.

4 En relación con el debate acerca de la noción de «imputación» del incumplimiento, véase BIANCA, C. M. Op. cit., p. 11 y ss.

5 LARENZ, K. Lehrbuch des Schuldrechts. 12. ${ }^{a}$ ed. Múnich, 1979, p. 21.

6 Véase BIANCA, C. M. Diritto civile, 4, L'obbligazione. Milán, 1993, p. 27 y ss.

7 Sobre esta concepción del patrimonio, véase FEDELE, P. «Patrimonio». Dizionario pratico di diritto privato. Vol. v. Milán, 1937-1939, p. 237 y ss. 
la atención en la responsabilidad patrimonial, con lo que se superaba la concepción romanista de la obligación como vínculo personal que liga a la persona del deudor con la del acreedor. Y no hay que olvidar que también se le ha atribuido el mérito de haber logrado, poco a poco, una significativa expansión de los regímenes de excepción al principio de la responsabilidad patrimonial ilimitada. ${ }^{8}$

Más allá de las razones que llevaron a la doctrina alemana a elaborar una teoría semejante, hay que destacar que la disyunción entre débito y responsabilidad termina envileciendo - tal es la palabra - el principio de juridicidad de la obligación como presupuesto necesario de la garantía social. ${ }^{9}$ Además, y a pesar de que en el sistema italiano se encuentran cada vez con mayor frecuencia — como veremos, claramente, más adelante- ${ }^{10}$ nuevas hipótesis normativas de limitación de la responsabilidad, estas no pueden ser consideradas como hipótesis de débito sin responsabilidad, porque la responsabilidad existe, aunque sea de modo reducido.

Es menester subrayar, de igual forma, que la conexión entre débito y responsabilidad responde a las más recientes tendencias del sistema de las garantías reales y de la responsabilidad patrimonial, encaminadas a dar más y más relevancia a la causa del crédito, sea por medio de la creación de privilegios especiales, ${ }^{11}$ sea por medio del reconocimiento legislativo de patrimonios destinados a un fin, los cuales comportan una desviación respecto de los principios generales de la responsabilidad patrimonial, atendiendo, justamente, al fin, y, por lo tanto, a la fuente del crédito. ${ }^{12}$

\section{Raíces históricas del principio de responsabilidad patrimonial ili-} mitada: la teoría francesa sobre la personalización del patrimonio y la teoría alemana de los «patrimonios destinados a un fin» (Zweckvermögen).

El principio de la garantía patrimonial hace su aparición recién en la época de las codificaciones ${ }^{13}$ como expresión, en el plano normativo, de las

\footnotetext{
Véase BIANCA, M. Vincoli di destinazione e patrimoni separati. Padua, 1996, p. 120.

9 En tal sentido, véase BIANCA, C. M. L'obbligazione. Op. cit., p. 26. Análogas son las reflexiones de NERVI, A. La responsabilità patrimoniale dell'imprenditore. Padua, 2001, p. 21 y ss.

10 Véase infra, $n .^{\circ} 4$

$"$ Véase tUCCI, G. "Concorso dei creditori, cause di prelazione e revocatoria fallimentare». En Diritto fallimentare. 2000, p. 597 y ss.

12 Al respecto, véase IAMICELI, P. Unità e separazione dei patrimoni. Padua, 2001, p. 119.

13 El principio de la responsabilidad patrimonial, en efecto, no aparece previsto expresamente
} 
reglas que las ideologías forjadas por la Ilustración iban predicando respecto de la indivisibilidad y unitariedad del patrimonio. Así, el Code Napoléon, de inicios del siglo XIX, fue el primero en el que se consagró el principio analizado al establecerse, en su artículo 2092, que "quiconque sest obligé personnellement, est tenu de remplir son engagement sur tous ses biens mobiliers et immobiliers, présents et à venir». ${ }^{14}$ En el artículo 1948 del Código Civil italiano de 1865 , se reproducía, sustancialmente, el contenido de tal disposición del Code Civil: "Chiunque sia obbligato personalmente, é tenuto ad adempiere le contratte obbligazioni con tutti $i$ suoi beni presenti e futuri». El Código Civil italiano de 1942 ha añadido a aquel contenido la prohibición expresa de establecer limitaciones de responsabilidad, salvo en los casos establecidos por la ley (art. 2740, 2. ${ }^{\circ}$ párrafo).

Los valores que el principio de responsabilidad patrimonial tiende a realizar y proteger son distintos, y no pueden agotarse en la pura protección del crédito. Al respecto, resulta significativo lo que se señala en la Relazione al Codice civile del Ministro de Gracia y Justicia, en la cual se hace mención, explícitamente, del valor colectivo de la economía, así como del valor individual del acreedor y de los intereses que el artículo 2740 apunta que se deben proteger. ${ }^{15}$ Debe subrayarse, asimismo, que, aun cuando el artículo

en la época anterior a las codificaciones, a pesar de que el referente económico de la exigencia de la circulación de los bienes ya había sido planteado, con toda su relevancia, en el pasado. En relación con este punto, pueden recordarse las leyes abolitivas que prohibían el fideicomiso, en particular la ley alemana del 21 de diciembre de 1848, referida por CROME, C. System des Deutschen bürgerlichen Rechts. T. III. Tubinga, 1905, $\S 447$, p. 584 (nota 18), y la ley francesa de octubre de 1792. En el ordenamiento italiano, la prohibición del fideicomiso se establecía en el Código del Reino de las Dos Sicilias, de 1819, y el Código Civil del Reino de Cerdeña, de 1837. Al respecto, véase la explicación histórica de RICCA, L. «Fedecommesso (dir. civ.)». En Enciclopedia del diritto. Vol. XVII. Milán, 1968, p. 114 y ss.; BENEDETTI, G. En Commentario alla riforma del diritto di famiglia. Editado por L. Carraro, G. Oppo y A. Trabucchi. T. I. Vol. 2. Padua, 1977, p. 876 y ss. Sobre la consideración de fideicomiso como instrumento que impide la circulación de la riqueza, véase GalGano, F. Diritto privato. Padua, 1992, p. 845; PutTI, P. "La sostituzione fedecommissaria prima e dopo la riforma del diritto di famiglia». En La Nuova giurisprudenza civile commentata. 1990, II, p. 421; TERZI, M. "Sostituzione semplice e sostituzione fedecommissaria». En Successioni e donazioni. Editado por P. Rescigno. I. Padua, 1994, p. 1153; BERNARDINI, M. "Sostituzione fedecommissaria». Rivista del notariato, 1993, p. 1081 y ss; IUDICA, G. "Fondazioni, fedecommesserie, trusts e trasmissione della ricchezza familiare». En Scritti in onore di Rodolfo Sacco. T. II. Milán, 1994, p. 641 y ss.; BONILINI, G. Il testamento. Lineamenti. Padua, 1995, p. 41 y ss.

14 PONT, P. Commentaire-Traité théorique et pratique des priviléges et hypothéques et de l'expropriation forcée mis en rapport avec la loi sur la transcription. T. 1. París, 1859, quien consideraba el artículo 2092 como un principio de alta moralidad.

15 «El principio fundamental de que el deudor responde del cumplimiento de las obligaciones con todos sus bienes presentes y futuros, y de que los acreedores, sin perjuicio de las causas legítimas de prioridad en la concurrencia, tienen igual derecho de satisfacerse a 
2740 hace referencia expresa a los bienes del deudor y remite, por lo tanto, a la noción de patrimonio, se trata de una norma destinada a proteger, en abstracto, la responsabilidad del sujeto deudor, y que no está dirigida a preservar el patrimonio del deudor, porque a este resultado se dirige, expresamente, la norma sobre la acción revocatoria (art. 2900 del Código Civil). En efecto, hay autorizada doctrina que resalta la distinción entre limitación de la responsabilidad y limitación del patrimonio. ${ }^{16}$ Dichas limitaciones han sido ubicadas en distintos ámbitos del sistema del derecho civil y comportan diversos juicios de valor por parte del ordenamiento. ${ }^{17} \mathrm{La}$ limitación de la responsabilidad constituye, ciertamente, una excepción al principio de universalidad de la responsabilidad patrimonial, contenido en el artículo 2740 del Código Civil. La limitación del patrimonio, por el contrario, se ve sancionada por medio del instrumento de la acción revocatoria. La distinción entre la noción de responsabilidad y la noción de patrimonio puede ser útil, en particular, para eliminar las dudas en torno de la suficiencia de la acción revocatoria para expresar el principio de responsabilidad patrimonial ilimitada. Estas son dudas que se plantean en aquellos ordenamientos que, como el peruano, a pesar de no haber codificado expresamente el principio de responsabilidad patrimonial ilimitada, sí prevén una regulación completa de la acción revocatoria. ${ }^{18}$ Un discurso distinto es el relativo a la concreta aplicación del principio de responsabilidad patrimonial ilimitada. Como se verá con mayor nitidez en las páginas que siguen, el marco actual

costa de ellos, es objeto de enunciación en los artículos 2740 y 2741, y es reforzado por la norma (2740, segundo párrafo) que, en el interés del crédito y de la economía, no permite limitaciones de responsabilidad fuera de los casos establecidos por la ley».

16 Nos referimos al pensamiento de FALZEA, Angelo. "Introduzione e considerazioni conclusive». En Destinazione di beni allo scopo. Strumenti attuali e tecniche normative. Actas de la Jornada de Estudio organizada por el Consiglio Nazionale del Notariato. Roma, Palazzo Santacroce, 19 de julio de 2003, publicadas en Quaderni romani di diritto commerciale. Editado por B. Libonati y P. Ferro-Luzzi. Milán, 2003, p. 31: "Aunque el artículo 2740 del Código Civil enlaza la responsabilidad con los bienes del sujeto, este nexo sirve solamente para aclarar que la responsabilidad patrimonial involucra al entero patrimonio, incluso al patrimonio futuro, del obligado, pero no, desde luego, para instaurar una relación cuantitativa entre la dimensión de la responsabilidad y la dimensión del patrimonio. En pocas palabras: así como el incremento del patrimonio no comporta una ampliación de la responsabilidad, tampoco la reducción de aquél comporta una limitación de ésta».

17 Véase FALZEA Angelo. Op. cit., p. 31: "A la limitación de la responsabilidad se aplica el artículo 2740 del Código Civil, lo que da como consecuencia la nulidad por ilicitud de los actos. [...] En cambio, para los actos que inciden directamente en el patrimonio, es de aplicación solamente la acción revocatoria, en caso de que se presenten sus presupuestos y condiciones».

18 Cfr. LEÓN, Leysser L. "La responsabilidad extracontractual. (Apuntes para una introducciòn al estudio del modelo juridico peruano)». Ahora en id. La responsabilidad extracontractual - Líneas fundamentales y nuevas perspectivas. Trujillo, 2004, § 7, p. 23 y ss. 
del sistema privatístico italiano revela un fenómeno de gradual erosión del principio contenido en el primer párrafo del artículo 2740 del Código Civil, a tal punto que se ha puesto en duda su supervivencia actual. ${ }^{19}$

Fuera de las reflexiones precedentes sobre el alcance aplicativo y concreto del principio de la responsabilidad patrimonial, se debe revelar que, en el sistema del derecho europeo, dicho principio, independientemente de su enunciación explícita, representaba, al momento de su génesis, el resultado de un planteamiento ideológico y conceptual que consideraba la unitariedad como elemento caracterizador e imprescindible del patrimonio, entendido como instrumento de satisfacción de la garantía creditoria. Expresión de esta concepción son las dos corrientes de pensamiento que han influido más en la teoría del patrimonio y la connotación de la indivisibilidad de este. Nos referimos, en especial, a la "teoría personalista del patrimonio", de proveniencia francesa, ${ }^{20}$ y a la teoría alemana de los "patrimonios destinados a un fin» (Zweckvermögenstheorie), forjada por la pandectística. En la primera, la unidad, y, por lo tanto, la indivisibilidad del patrimonio, está dada por el sujeto que es su titular. La consideración del patrimonio como emanación de la personalidad tiende a fotografiar una realidad patrimonial cuyos rasgos sistemáticos encuentran un referente unitario en la noción misma de «subjetividad

9 Véase infra, $n .^{\circ} 3$.

20 La primera formulación de la teoría personalista del patrimonio se encuentra en la obra de AuBRY, G. y G. RAU. Cours de droit civil français. 1. ${ }^{a}$ ed. Estrasburgo, 1839; 2. ${ }^{a}$ ed. Estrasburgo, 1850; y la tercera edición, inspirada expresamente en la obra alemana ZACHARIAE, C. S. Cours de droit civil français d'après l'ouvrage de C. S. Zachariae. París, 1857-1858, que tuvo dos ediciones posteriores: la 4. ${ }^{a}$ ed., en 1873, y la 5. ${ }^{a}$ ed., en 1917, a la cual haremos referencia de aquí en adelante. En el tomo Ix de la obra, § 573, p. 333, se lee: "L'idée de patrimoine se déduit directement de celle de la personnalité», mientras que, en la p. 336, se lee: "Le patrimoine est, en principe, un et indivisible comme la personnalité même». (La obra de Aubry y Rau tuvo varias traducciones al italiano. Véase, por ejemplo, el Corso di diritto civile francese sull'opera allemanna di C. S. Zachariae per Aubry e Rau. Versión italiana con notas por C. Muzj. 3. ${ }^{a}$ ed. T. III. Nápoles, 1858, § 573 y ss., p. 5 y ss; Corso di diritto civile francese per C. S. Zachariae. Revisado y anotado, con el consentimiento del autor, por Aubry y Rau. Nueva traducción italiana por F. Fulvio. T. I. Nápoles, 1868, p. II, §573 y ss., 261 y ss.).

El pensamiento de Aubry y Rau fue adoptado por gran parte de la doctrina clásica italiana. Véase, por ejemplo, BIANCHI, F. S. Corso di diritto civile italiano. Vol. IX. Parte I. Turín, 1895, § 2, p. 7: "El patrimonio constituye una universalidad jurídica, que emana de la personalidad misma de aquel a quien pertenecen los bienes». Sin embargo, el citado autor, a pesar de adoptar la concepción general del patrimonio como emanación de la personalidad, discrepa de los autores franceses en lo tocante a la comprensión, en la masa patrimonial, de los bienes futuros, en tanto juzga negativamente lo que de abstracto tiene una afirmación semejante. VIVANTE, C. "Comentario a la sentencia de la Corte d'Appello di Bologna, del 8 de junio de 1888». En Il Foro italiano, 1888, I, col. 940, quien, discrepando en relación con la autonomía de la azienda, subraya que esta afirmación debe considerarse "anti-jurídica, porque una persona no tiene más que un solo patrimonio, cualquiera que sea el fin al que destine los bienes que lo componen». 
física» y cuyos corolarios son la consideración del patrimonio como requisito de la persona, ${ }^{21}$ la unicidad y la indivisibilidad de este y la negación de la pertenencia de una pluralidad de patrimonios a un mismo titular. ${ }^{22}$

En la teoría de los patrimonios destinados a un fin, la unidad del patrimonio no está dada por el sujeto, sino, en clave objetiva, por el fin. Un patrimonio puede pertenecer no solo al sujeto, sino también a un fin, de acuerdo con la conocida formulación de Brinz. Dicha teoría, que, en su primera formulación, parece dejar a un lado al sujeto titular, arriba, en sus elaboraciones posteriores, a las mismas paradojas de la teoría personalista del patrimonio. Los patrimonios destinados a un fin devienen, en efecto, patrimonios personificados a imagen y semejanza de las personas jurídicas.

Aunque siguiendo caminos distintos, ambas teorías llegan a afirmar el mismo principio de indivisibilidad del patrimonio y niegan toda posible fragmentación y limitación de la responsabilidad patrimonial.

\section{Mixtura entre la noción de personalidad jurídica y la noción de patrimonio separado}

Este planteamiento subjetivista ha determinado consecuencias considerables en la interpretación del principio de la responsabilidad patrimonial y de sus limitaciones. El dogma de la indivisibilidad del patrimonio ha tenido tal influencia en nuestro sistema que, en el pasado, se admitía única-

21 Algunas críticas a dicha teoría ponen en evidencia la confusión entre capacidad patrimonial y patrimonio, la cual deriva de la identificación entre personalidad y patrimonio (Coviello, N. Manuale di diritto civile italiano. Parte generale. 4. ed. Vol. I. Milán, 1929, p. 253; VituCCI, E. "Patrimonio». Nuovo Digesto italiano. Vol. IX. Turín, 1939, p. 559). A decir verdad, tales críticas fueron el resultado de una errada interpretación de la teoría personalista del patrimonio, que considera el patrimonio como emanación de la personalidad, pero no como sustituto de esta. En efecto, de la lectura de la obra de Aubry y Rau se deduce claramente que el patrimonio conserva el papel de atributo de la personalidad, sin sufrir un proceso de fusión con asimilación (AUBRY, G. y G. RAU. Op. cit., p. 347).

22 Véase AuBry, G. y G. RAU. Op. cit., § 573, p. 335: "Le patrimoine étant une émanation de la personnalité, est l'expression de la puissance juridique dont une personne se trouve investie comme telle, il en résulte: que le personnes physiques ou morales peuvent seules avoir un patrimoine; que toute personne a nécessairement un patrimoine, alors même qu'elle ne posséderait actuellement aucun bien; que la même personne ne peut avoir qu'un seul patrimoine, dans le sens propre du mot». La consideración del patrimonio como expresión del poder jurídico es ejemplificada, según Bianchi, por la noción ambivalente de la terminología alemana, donde la palabra Vermögen indica, al mismo tiempo, tanto el patrimonio cuanto la potestad: BIANCHI, F. S. Op. cit., § 2, p. 8; BAUDRYLACANTINERIE, G. y A. WAHL. Trattato teorico-paratico di diritto civile. s.f., § 1, p. 2: "toda persona tiene, necesariamente, un patrimonio, aun cuando no posea nada; el patrimonio [...] es una emanación de la personalidad». 
mente la legitimidad de las llamadas limitaciones «personificadas» de la responsabilidad patrimonial,o bien de las consiguientes a la creación de un nuevo sujeto jurídico. El arduo debate doctrinal sobre la inadmisibilidad de la fundación no reconocida nace, justamente, del impedimento ideológico respecto de un instrumento como la fundación no reconocida, que permite la destinación del patrimonio, con la consecuente especialización de la responsabilidad patrimonial, sin el crisma formal de la personalidad jurídica. También las distintas elaboraciones doctrinales sobre el concepto de patrimonio separado, entendido como patrimonio perteneciente al mismo sujeto, pero sujeto a una regla diferente de responsabilidad patrimonial, testimonian una peculiar tendencia a ubicar el tema de la separación patrimonial en el ámbito de las problemáticas de la subjetividad y de la personalidad jurídica. ${ }^{23} \mathrm{Y}$, en tiempos más recientes, existe autorizada doctrina que destaca la fungibilidad del instrumento de la personalidad jurídica y de la separación del patrimonio para permitir formas de limitación de la responsabilidad patrimonial. ${ }^{24}$ Dicha fungibilidad resulta confirmada en el nivel normativo, inclusive, dada la posibilidad que se ha dado a los países miembros de la Unión Europea, con la XII directiva comunitaria en materia de sociedades, para optar por el modelo de la sociedad unipersonal o de la empresa individual de responsabilidad limitada. La elección de la mayoría de los países miembros, favorable al modelo societario, ha sido explicado, ni más ni menos, sobre la base del convencimiento ideológico en lo tocante al principio de indivisibilidad del patrimonio, principio que resultaría formalmente invulnerable por medio del empleo de la vestidura de la personalidad jurídica y, por lo tanto, del modelo de la sociedad unipersonal.

También la reciente reforma del derecho de sociedades italiano, al introducir la nueva institución de los patrimonios destinados a un negocio específico, como hipótesis de fraccionamiento del patrimonio de las sociedades anónimas, justifica aquella elección en la exigencia de reducir los costos de la constitución de una nueva sociedad, con lo que se confirma la fungibilidad del instrumento del fraccionamiento del patrimonio y de la creación de una nueva persona jurídica.

En el nivel sistemático, el ordenamiento italiano muestra una orientación coherente, dirigida a conseguir el resultado de la limitación de la responsabilidad patrimonial, sea de la consiguiente a la creación de un nuevo

Sobre la evolución de las teorías subjetivas hacia las teorías objetivas del patrimonio separado, remitimos a BIANCA, M. Vincoli di destinazione e patrimoni separati. Op. cit., especialmente el capítulo II.

24 SPADA, P. «Persona giuridica e articolazioni del patrimonio: spunti legislativi per un recente dibattito». Rivista di diritto civile, 2002, I, p. 837 y ss. 
sujeto de derecho, sea de la consiguiente al fraccionamiento del patrimonio del deudor.

En relación con las limitaciones personificadas, las medidas tomadas por el legislador en el último quinquenio han apuntado a permitir una facilitación del procedimiento de constitución de la persona jurídica. Para las entidades del libro I, la simplificación del procedimiento ha tenido lugar con el decreto del Presidente de la República 361, del 10 de febrero del 2000, cuyo artículo 1, al prever el conferimiento de la personalidad jurídica mediante la inscripción en el registro de las personas jurídicas, ha abrogado el artículo 12 del Código Civil, basado en el sistema concesorio. La simplificación del procedimiento de adquisición de la personalidad jurídica es, además, uno de los objetivos en los cuales se inspira el proyecto de reforma general del libro I. ${ }^{25}$ Desde el punto de vista sustancial, la nueva regulación exige, como únicos requisitos del fin de la entidad, la posibilidad y la licitud (art. 1, 3. párrafo, del citado decreto). La doctrina, por lo tanto, considera que el reconocimiento de asociaciones y fundaciones ya no está ligado a la relevancia pública del fin. ${ }^{26}$ Para las entidades del libro V, una análoga simplificación ha sido dispuesta por el artículo 32 de la ley 340 del 24 de noviembre de 2000, que ha suprimido la fase de homologación del tribunal, simplificación posteriormente confirmada en el marco de la reforma societaria.

También para las limitaciones no personificadas de la responsabilidad patrimonial, la reciente legislación especial denota una proliferación de hipótesis típicas de limitación de la responsabilidad patrimonial. Todas estas hipótesis están vinculadas con fenómenos peculiares del sector financiero: desde las distintas leyes sobre la gestión del patrimonio hasta el fenómeno de la securitización de los créditos. Se trata, en definitiva, de separaciones del patrimonio que tienen relación, todas ellas, con fenómenos típicos. De distinto tenor es la institución de los patrimonios destinados a un negocio específico, institución creada por la reciente reforma del derecho de sociedades y regulada por los artículos 2447-bis y siguientes del Código Civil. ${ }^{27}$ Aquí la diversidad respecto de las disposiciones normativas precedentes se

Véase la delegación de facultades al Gobierno para la reforma de las personas jurídicas y de las asociaciones no reconocidas reguladas en el libro I del Código Civil. Al respecto, consúltese Nuzzo, M. "Una disciplina da svecchiare». Il sole 24-Ore, edición del 11 marzo de 2004; y GIORGI, M. V. de. En Studium iuris, 2000, p. 499.

26 Véase ZoppinI, A.; G. Ponzanelli, y M. V. de Giorgi (eds.). Il riconoscimento delle persone giuridiche. Milán, 2002, p. 19.

27 Entre los mejores estudios que se han realizado acerca de esta nueva institución hay que señalar el de TONDO, S. "Patrimoni destinati ad uno specifico affare». En Studi e materiali. Consiglio Nazionale del Notariato, 2004, p. 1 y ss. Para ulteriores referencias bibliográ- 
aprecia, principalmente, en el hecho de que la separación del patrimonio no tiene que ver con un fenómeno particular, sino que es una opción general que el legislador prevé para un tipo societario: el de la sociedad anónima. Sin embargo, la doctrina considera que también en relación con los patrimonios de destinación societaria se permanece en el ámbito de las limitaciones de responsabilidad de fuente normativa y, por lo tanto, se mantiene la coherencia con el contenido del segundo párrafo del artículo 2740 del Código Civil, en tanto y en cuanto estamos ante una limitación dispuesta por el legislador. ${ }^{28}$

\section{Distinción entre patrimonios separados «estáticos» del Código Civil y patrimonios separados «dinámicos» de la legislación especial en materia financiera. Significado y relevancia de dicha distinción}

Los cambios normativos que hemos descrito sintéticamente imponen nuevas reflexiones acerca de la actual lectura del artículo 2740 del Código Civil $y$, en general, sobre la vigencia del principio de indivisibilidad del patrimonio. La proliferación de nuevos instrumentos de limitación de la responsabilidad patrimonial, sea por medio del procedimiento simplificado de adquisición de la personalidad jurídica, sea por medio de la fragmentación del patrimonio, induce al intérprete a interrogarse sobre el actual fundamento del principio de responsabilidad patrimonial. En el pasado, el fundamento de este principio y de la prohibición de imponer limitaciones a él debía encontrarse en la exigencia de no inmovilizar la riqueza. A esta exigencia real se añadía, luego, el peso del dogma de la indivisibilidad del patrimonio, que volvía inaceptable toda hipótesis de fragmentación del patrimonio individual. En los primeros códigos civiles, así como en el actual, las limitaciones de responsabilidad patrimonial de fuente legal constituían una excepción. Los ejemplos que se formulaban eran instituciones hoy suprimidas, como la dote y el patrimonio familiar, el fideicomiso y la regulación actual del fondo patrimonial. Estas instituciones se caracterizaban, unánimemente, por presentarse como instrumentos de inmovilización de la riqueza. De aquí se derivaba el carácter excepcional del recurso a tales instrumentos. Desde esta perspectiva, el principio de la responsabilidad patrimonial era

ficas y para un comentario sistemático, artículo por artículo, véase BIANCA, M. "Dei patrimoni destinati ad uno specifico affare (artt. 2447 bis - 2447 decies)». En CIAN, G. y A. TrabuCCHI. Commentario breve al codice civile. 7. ${ }^{a}$ ed. Padua, 2004.

28 Véase ZOPPINI, A. "Autonomia e separazione del patrimonio nella prospettiva dei patrimoni separati della società per azioni». Rivista di diritto civile, 2002, I, p. 545; QUADRI, R. La destinazione patrimoniale. Nápoles, 2004, p. 324. 
considerado como norma de orden público. Por lo tanto, se consideraban nulos, en tanto y en cuanto contrarios al orden público, los actos mediante los cuales se reconocían instituciones extranjeras como el Anstalt o el trust.

En el sistema normativo de hoy en día, parece haber cambiado, precisamente, el fundamento del principio de la responsabilidad patrimonial y de la prohibición de limitaciones a él. El fundamento de la multiplicación de las limitaciones de responsabilidad responde a un principio de naturaleza económica, que propende a la realización de los valores del provecho y de la eficiencia. ${ }^{29}$ Con particular referencia a la actividad empresarial, la especialización de la responsabilidad patrimonial permite realizar diversos efectos de eficiencia para el sistema, entre los cuales se cuenta la posibilidad, para el empresario, de diversificar y organizar su propia actividad en distintos compartimientos, con el fin de reducir los riesgos de pérdidas en determinados sectores; esta ventaja va de la mano con otra: la reducción de los costos de monitoreo del crédito. ${ }^{30}$ No es casualidad que la doctrina estadounidense $^{31}$ revele las ventajas económicas de la especialización de la responsabilidad, la llamada "asset partitioning», ventajas que se manifiestan, sobre todo, cuando la separación patrimonial tiene lugar en los sectores de la empresa y de las finanzas. Hay que destacar, sin embargo, que, en las reflexiones de esta doctrina, la especialización de la responsabilidad patrimonial, con sus respectivos beneficios, está ligada, de modo imprescindible, con el elemento

29 Para estas reflexiones, véase BIANCA, M. "Dei patrimoni destinati ad uno specifico affare (artt. 2447 bis - 2447 decies)». Op. cit., p. 242.

30 Véase, al respecto, y más ampliamente, el cuidadoso análisis de SANTAGATA, $R$. "Capítulo I». Patrimoni destinati e rapporti intergestori. § 1, de próxima publicación por la editorial Giappichelli (texto que hemos podido consultar gracias a la cortesía del autor); COURIR, E. Limiti alla responsabilità imprenditoriale e rischi dei terzi. Milán, 1997; GALLETTI, D. "Il creditore particolare del socio». Quaderni di giurisprudenza commerciale. Milán, 2002, p. 42 y ss.; IAMICELI, P. Op. cit., p. 148 y ss. Para un estudio de la responsabilidad patrimonial del empresario, véase lo que ya indicaba NERVI, A. Op. cit., passim.

31 Véase HANSMANN, H. y R. KRAAKMAN. "The Essential Role of Organization Law». Yale Law Journal, 2000, p. 387. Particularmente significativa para los autores estadounidenses, por el aspecto de la eficiencia, es la llamada affirmative asset partitioning, que permite una selección entre los diversos acreedores y constituye un específico producto de organizational law. Sobre el enlace, en general, entre el fenómeno de la especialización de la responsabilidad y el agency law, veáse THOMPSON, R. "Agency Law and Asset Partitioning». University of Cincinnati Law Review, 2003, p. 11 y ss. En la doctrina italiana, estas reflexiones han conducido a plantear la hipótesis de que la separación patrimonial, antes que presentarse como límite a la propiedad, puede ser un modo de ejercicio de ésta: IAMICELI, P. Op. cit., p. 70 y ss. Parece ser, sin embargo, que, si se pretende asentir a esta última afirmación, ella debe ser utilizada, más correctamente, para la destinación. En efecto, es el acto de destinación el que puede determinar un modo de ejercicio de la propiedad y no la separación, que, aun cuando derivada, naturalmente, del acto de destinación, se refiere solo al aspecto de la limitación de la responsabilidad patrimonial. 
organizativo de la corporación, y no puede realizarse en ausencia de este. ${ }^{32}$ Análogas reflexiones se detectan en aquella parte de la doctrina italiana que limita y sectoriza las ventajas de la especialización de la responsabilidad patrimonial con la actividad de empresa, con el enlace de dicho fenómeno, en general, con la estructura organizativa de las entidades ${ }^{33}$ o, en particular, con la estructura societaria de la sociedad anónima. Esta última reflexión conduce a limitar la aplicación de la nueva regulación de los patrimonios destinados a un negocio específico al modelo societario de la sociedad anónima (società per azioni), con lo cual se evita toda aplicación analógica y toda afinidad con destinaciones que operan en otros sectores (familiar, sucesorio). ${ }^{34}$

El análisis de la reciente evolución del sistema italiano muestra un dato indiscutible: la creación de nuevas figuras normativas de patrimonios separados opera, exclusivamente, en los sectores crediticio y financiero, porque justamente en estos sectores — como ya hemos destacado- la especialización de responsabilidad patrimonial se revela como un instrumento ventajoso y eficiente. La diferenciación entre patrimonios separados «estáticos»y patrimonios separados "dinámicos», ${ }^{35}$ aun cuando puede ser interesante desde el punto de vista descriptivo, no resuelve el problema general de la vigencia actual del principio de responsabilidad patrimonial ilimitada y del espacio concedido a los particulares en la creación de excepciones a la regla.

Es seguro que la actitud del jurista y del intérprete ha experimentado una profunda transformación. La antigua actitud de desconfianza y hostilidad frente a instituciones que concretizaban diversas formas de separación del patrimonio ha sido reemplazada por una actitud opuesta, de atracción frente a instituciones que realizan una especialización de la responsabilidad patrimonial, con efectos de competitividad para el sistema. Este fenómeno ha sido etiquetado con una feliz expresión: «la carrera hacia los patrimonios separados». ${ }^{36} \mathrm{Al}$ respecto, en el sistema italiano se ha manifestado una actitud de euforia en relación con la institución anglosajona del trust, euforia que, a

32 Cfr. el antes citado ensayo de HANSMANN, H. y R. KRAAKMAN, p. 387 y ss.

33 Véase, en particular, NERVI, A. Op. cit., p. 236 y ss., quien arriba a la conclusión de que "es la propia estructura organizativa la que asume la vestidura de deudor frente a los terceros».

34 Esta es, a nuestro parecer, la idea de fondo del trabajo de SANTAGATA, R. Patrimoni destinati e rapporti intergestori. Op. cit., passim.

35 Sobre este fenómeno, véase BIANCA, M. "Amministrazione e controlli nei patrimoni destinati». En Destinazione di beni allo scopo. Strumenti attuali e tecniche innovative. Op. cit., p. 161 y ss.

36 Véase GAmbaro, A. "Il diritto di proprietà». En Trattato di diritto civile e commerciale diretto da Antonio Cicu e Francesco Messineo, continuato da Luigi Mengoni. Vol. VIII. T. 2. Milán, 1995, p. 642. 
menudo, ha opacado la lucidez de las soluciones. ${ }^{37}$ En el aspecto técnico, esta apertura ha determinado un importante efecto reflejo: el principio de responsabilidad patrimonial ilimitada ha sido privado de la carga dogmática del principio de la indivisibilidad del patrimonio, que cumplía una función de orden público, ${ }^{38}$ aunque la reciente jurisprudencia casatoria ha desempolvado, esporádicamente, su antigua función. ${ }^{39}$

\section{Limitaciones de la responsabilidad patrimonial y autonomía pri- vada. Los intentos de la doctrina para superar la reserva de ley contenida en el segundo párrafo del artículo 2740 del Código Civil italiano}

La evolución descrita hasta este punto se detiene, sin embargo, frente a la solución del principal problema relativo al principio de responsabilidad patrimonial: el espacio reservado a la autonomía privada. Al respecto, el Código Civil italiano ha tomado una posición clara al establecerse, en el segundo párrafo del artículo 2740, una reserva de ley para las limitaciones de la responsabilidad patrimonial: «Las limitaciones de la responsabilidad patrimonial no se admiten, salvo en los casos establecidos por la ley». El principio de la responsabilidad patrimonial ilimitada, a pesar de no ser considerado más como norma de orden público, se mantiene como norma que no admite excepciones. La antes destacada distinción entre patrimonios separados de la empresa y patrimonios separados que operan en otros sectores, si bien revela, desde el punto de vista económico, la novedad y las ventajas de una especialización del patrimonio que opera en términos dinámicos y que, por ello, parece reservada al desenvolvimiento de actividades, no resuelve el problema de la superación de la reserva de ley contenida en el

\footnotetext{
37 Nos referimos, en particular, a aquellas soluciones que, con el fin de introducir forzosamente esta institución en nuestro sistema, han atribuido al Convenio de La Haya, sobre el reconocimiento de los trusts, y a la ley italiana de ratificación de dicho Convenio, una naturaleza distinta de la que es propia de las normas de derecho internacional privado. En relación con este debate, remitimos a BIANCA, M. La fiducia attributiva. Turín, 2001, p. 6 (nota 13).

38 Sobre la consideración del artículo 2740, $10^{\circ}$ párrafo, del Código Civil, no ya como principio de orden público, sino como norma que no admite excepciones, véase BIANCA, M. La fiducia attributiva. Op. cit., p. 89 y ss.; MASI, A. «Destinazione di beni e autonomia privata». En Destinazione di beni allo scopo. Strumenti attuali e tecniche innovative. Op. cit., p. 235 y ss.

39 Véase Corte di Cassazione, sentencia 8090, del 28 de abril del 2004 (inédita). Resulta bastante significativo que, en los fundamentos de esta sentencia, se siga haciendo referencia al principio de la indivisibilidad del patrimonio, entendido en su acepción originaria como "normal correspondencia entre subjetividad y unicidad del patrimonio».
} 
segundo párrafo del artículo 2740 del Código Civil. En relación con este punto, parecen uniformarse las reflexiones de la doctrina del derecho civil y comercial en lo tocante a la imposibilidad para los particulares de fijar limitaciones de la responsabilidad patrimonial mediante un acto de autonomía negocial, en tanto la elección del fin ha sido reservada a la decisicón del legislador. ${ }^{40}$

El problema de conceder un espacio a la autonomía negocial se ha planteado en relación con los actos negociales de destinación con efecto de separación patrimonial y, por lo tanto, de limitación de la responsabilidad patrimonial.

El intento de superar la reserva de ley ha llevado a parte de la doctrina a separar el acto de destinación y el efecto de separación, considerado como un efecto accesorio e instrumental respecto del acto programático de destinación del patrimonio, que sería el resultado del acto de autonomía negocial. ${ }^{41}$

Dichas reflexiones, que subrayan, ciertamente, la importancia de la distinción entre el acto programático de destinación y el acto que tiene como único fin la limitación de la responsabilidad patrimonial; que nos recuerdan, con ello, que la distinción es un concepto que no pasa, necesariamente, por los márgenes del artículo 2740 del Código Civil; y que desenvuelven, es más, una función autónoma en instituciones como las universalidades y los accesorios, se revelan insuficientes, sin embargo, cuando de la referencia

40 Esta solución, no obstante las diversas argumentaciones a las que ha dado lugar, resulta unívoca. Véase, al respecto, SANTAGATA, R. Op. cit. Capítulo I, § 1, quien, atendiendo, justamente, al específico interés de la empresa en la asunción de los riesgos conexos con el negocio, justifica y legitima la excepción al primer párrafo del artículo 2740 del Código Civil; Salamone, L. Gestione e separazione patrimoniale. Padua, 2001, p. 368, quien está de acuerdo con la taxatividad de los patrimonios separados, aun cuando considera que dicho carácter taxativo debe ser entendido en términos de oponibilidad del acto dispositivo a los acreedores; ZOPPINI, A. "Autonomia e separazione del patrimonio nella prospettiva dei patrimoni separati della società per azioni». Op. cit., p. 545 y ss.; IAMICELI, P. Op. cit., p. 102 y ss., quien, a pesar de destajar la ventaja económica de la especialización de la responsabilidad patrimonial, termina asignando al legislador la tarea de componer el conflicto de intereses; QUADRI, R. Op. cit., quien destaca el contenido constitucional de la norma sobre la protección del crédito.

41 Véase, en particular, PALERMO, G. "Autonomia negoziale e fiducia (breve saggio sulla libertà delle forme)》. Rivista giuridica Sarda, 1999, p. 571 y ss.; id. "Sulla riconducibilità del "trust interno» alle categorie civilistiche». Rivista del diritto commerciale e del diritto generale delle obbligazioni, 2000, p. 133 y ss.; id. "Contributo allo studio del trust e dei negozi di destinazione disciplinati dal diritto italiano». Rivista del diritto commerciale e del diritto generale delle obbligazioni, 2001, p. 391 y ss.; id. "Ammissibilità e disciplina del negozio di destinazione». En Destinazione di beni allo scopo. Strumenti attuali e tecniche innovative. Op. cit., p. 243 y ss.; LA PORTA, U. Destinazione di beni allo scopo e causa negoziale. Nápoles, 1994; id. "Causa del negozio di destinazione e neutralità dell'efffetto traslativo». En Destinazione di beni allo scopo. Strumenti attuali e tecniche innovative. Op. cit., p. 261 y ss. Contrario a la consideración de la separación como efecto secundario del acto negocial de destinación, véase QUADRI, R. Op. cit., p. 324 y ss. 
genérica a la destinación se pasa a la referencia técnica al patrimonio de destinación. El patrimonio de destinación es siempre un patrimonio separado, que, por lo tanto, comporta una excepción al principio de responsabilidad patrimonial ilimitada, porque es, justamente, la referencia al patrimonio la que conlleva, como efecto principal, la separación. Debe afirmarse, entonces, que aquí la separación no es un efecto secundario e instrumental, sino un efecto necesario, sin el cual no se podría ni siquiera hablar de destinación patrimonial.

Lo que hay que entender, por lo tanto, es en qué ámbito puede tener lugar, y con qué contenido, el acto de autonomía privada. Si se analizan las recientes figuras de patrimonios destinados, dispuestas por el legislador, parece que se ha quitado a los particulares nada más que el efecto de la oponibilidad del vínculo de destinación, mientras que es eadmisible una elección de las finalidades programáticas del acto de destinación, con el único límite previsto para todos los actos de autonomía privada, a saber: que el interés sea merecedor de protección (art. 1322, 2. ${ }^{\circ}$ párrafo del Código Civil). Un acto negocial de destinación que tuviera como única finalidad librar el patrimonio del deudor de la afectación por parte de los acreedores sería, automáticamente, un acto que no merecería protección. No obstante ello, se ha descartado de la autonomía de los particulares la elección de las modalidades por medio de las cuales el vínculo de destinación se hace oponible a los terceros. Así pues, la intervención del legislador debería hacer referencia únicamente al aspecto de la separación. Al respecto, sería de auspiciar que el legislador dispusiera la inscripción de los actos de destinación relativos a bienes inmuebles y biene muebles registrados, sin perjuico de la evaluación del contenido de la destinación, para establecer si el interés al que esta obedece es merecedor de la protección jurídica. 